\title{
A. Tarskiego kryterium monotoniczności operatora konsekwencji w międzykulturowych badaniach systemów wnioskowań
}

\author{
Stawomir Sikora \\ INSTYTUT JĘZYKOZNAWSTWA, UNIWERSYTET IM. ADAMA MICKIEWICZA \\ AL. NIEPODLEGŁOŚCI 4, 61-874 POZNAŃ \\ slsikoralamu.edu.pl
}

\begin{abstract}
In this article I refer to the issue of comparative research methodology and methods of philosophical argumentation systems with different cultural areas.

In relation to that shown by A. Tarski logical consequence operator, will establish criteria for the comparative analysis of systems inferences different cultural areas of the property based on the operator monotonic consequences.
\end{abstract}

Artykuł stanowi sprawozdanie z pierwszej część badań nad kryterium monotoniczności $\mathrm{w}$ badaniach porównawczych systemów wnioskowań $\mathrm{w}$ obszarach odmiennych kulturowo.

Badania podzielone było na trzy części:

1. Własności monotoniczności operatora konsekwencji logicznej i jego aplikacja w badaniach międzykulturowych.

2. Własność monotoniczność operatora konsekwencji wybranego systemu wnioskowania kultury indyjskiej - analiza systemu Dignagi;

3. Implementacja metody porównawczej w badaniach międzykulturowych.

Badania prowadziłem w Zakładzie Logiki Stosowanej w latach 20132014. Wyniki były prezentowane $\mathrm{w}$ ramach seminarium Zakładu Logiki Stosowanej 11.01.2014 r.

$\mathrm{W}$ artykule stanowiącym sprawozdanie $\mathrm{z}$ pierwszej części badań przedstawiam podstawową problematykę metodologii badań porównawczych logiki oraz sposobów argumentacji w systemach filozoficznych z obszarów odmiennych kulturowo. W oparciu o przedstawianą przez A. Tarskiego definicję operatora konsekwencji logicznej, ustanawiam kryterium wlasność monotoniczności operatora konsekwencji $\mathrm{w}$ analizie porównawczej dla systemów wnioskowań $\mathrm{z}$ obszarów odmiennych kulturowo.

Dotychczasowe badania z zakresu systemów logicznych w różnych obszarach kulturowych pokazały, że główne tradycje filozoficzne 
współczesnej cywilizacji człowieka: zachodnia, indyjska i chińska, cechują się wysokim stopniem niezależności w tej sprawie (Harbsmeier 1998: 125). Często stanowią one zamknięte terminologicznie i pojęciowo zbiory systemów kulturowych, które, co wynika z dotychczasowej praktyki badań porównawczych, z trudem znoszą obce implantacje. Zakładam, zatem, że wyróżnione w poszczególnych tradycjach systemy logiczne rozwijały się niezależnie, w różnych kontekstach kulturowych.

Jednym z podstawowych problemów komparatystyki systemów takich logik jest wybór metody badań. Na poziomie opisu przedmiotu badań metoda winna zobligować badacza na wskazanie zagadnień logicznych, które mimo pewnych różnic, są wspólne obu porównywanym tradycjom. Za przykład $w$ tym względzie służyć może forma sylogizmu jako podstawowa struktura wnioskowania, rozpoznawalna $\mathrm{w}$ kulturze zachodniej i indyjskiej (Radhakirishna 1948:75-86). Sylogistyczna forma wnioskowań natomiast nie znalazła uznania w kulturze chińskiej.

Jako odrębny przedmiot badawczy należy również wyróżniać te zagadnienia, które chociaż mają swoje trwałe miejsce w ogólnej problematyce filozoficznej, poświęconej prawomocności systemów uzasadniana wiedzy, są specyficzne tylko dla danej tradycji kulturowej i nie odnajdziemy ich w tradycji innej np.: funkcja paradoksu w logice chińskiej. ${ }^{1}$

W proponowanej przeze mnie metodologii badań porównawczych pod pojęciem modelu wyjaśniania sytemu wnioskowań będę rozumiał dwustopniową strukturę, w której pierwszy element jest teoretycznym opisem badanego systemu wnioskowań w ramach zadeklarowanego sposobu eksplanacyjnego z wyróżnioną siatką pojęć i reguł. Drugim zaś, jest struktura formalna, w której próbujemy odwzorować otrzymany model deskryptywny.

Częstym błędem metodologicznym w dotychczas podejmowanych badaniach z zakresu logiki porównawczej było założenie, że drugi element modelu jest zawsze możliwy do skonstruowania². Dziś wiemy, że proces wyjaśniania sformułowanego problemu może być zamknięty na etapie pierwszym. W postulowanej przeze mnie metodologii badań porównawczych dla logiki i systemów argumentacji, proponuje się, aby konstruowany model uwzględniał preferowane w analizowanych kulturach koncepcje ontologiczne, epistemologiczne (w szczególności koncepcje reprezentacji wiedzy), koncepcje znaczenia, a nawet w uzasadnionych przypadkach, systemy przekonań religijnych. Z kolei na etapie konstrukcji formalnej mającej odzwierciedlać teoretyczny opis danego zjawiska argumentacyjnego, dobór struktury logicznej (rachunku) powinien uwzględniać:

\footnotetext{
${ }^{1}$ Zob. artykuł S. Sikory Metody budowy pojęcia zbioru w problemie interpretacji tez Hui Shi (Sikora 2010).

2 Ze względu na trafność i klarowność analizy problemów konstrukcji modelu interpretaycjnego dla wnioskowań buddyjskich w literaturze polecam pracę D. D. Daye Metalogical incompatibilittes in the formal description of buddhist logic (nyaya) (Daye 1977).
} 
Stawomir Sikora: A. Tarskiego kryterium monotoniczności operatora konsekwencji w międzykulturowych badaniach systemów wnioskowań

1. Aspekt translacyjno - syntaktyczny; dotyczy doboru właściwych środków operacyjnych, uwzględniający możliwość przekładu z języka naturalnego, w którym sformułowane jest wnioskowanie na język teorii formalnej. Na przykład język chiński jest morfologicznie językiem izolującym tzn., że większość występujących w nim morfemów ma samodzielne znaczenie a funkcja logiczna klasyfikatorów przed rzeczownikowych często nie pozwala na tak dokładne formalne odwzorowanie zdań (pojedynczych jak i tych ze spójnikami prawdziwościowym), jak ma to miejsce w przypadku języków indoeuropejskich.

2. Aspekt semantyczno - pragmatyczny; dotyczy doboru właściwej koncepcji prawomocności stwierdzeń formułowanych $\mathrm{w}$ ramach przyjętej teorii wnioskowań.

$\mathrm{Na}$ przykład, szeroko rozpowszechniona w filozofii zachodniej relacyjna koncepcja prawdziwości zdań Arystotelesa nie jest adekwatnym narzędziem do modelowania systemów wnioskowań logików buddyjskich, którzy zdecydowanie opowiadają się za epistemiczną koncepcją prawdy 3.

3. Aspekt porządkujący uniwersum dyskursu; pozwala na dobór właściwych metod porządkujących przestrzeń ontologiczną dla teorii wnioskowań. Porządki owe (w sensie formalnym) powinny być odzwierciedleniem preferowanych $\mathrm{w}$ danej kulturze różnych funkcji, przypisanym do pojęcia zbioru (porzadki mereologiczne, porządki dystrybucyjne) oraz ich w tym względzie filozoficznych zobowiązań (np. arystotelejski uniwersalizm, nominalizm Leśniewskiego). Dla przykładu, w odróżnieniu od preferencji tradycji zachodniej z porządkiem dystrybutywnym, w rozumowaniach filozofów chińskich preferowanym porządkiem przestrzeni ontologicznej jest porządek mereologiczny (Sikora 2010).

4. Aspekt monotoniczności analizowanych wnioskowań; umożliwia klasyfikację wnioskowań ze względu na rodzaj relacji między przesłankami a konkluzją. Kryterium, na którym zasadza się dobór koncepcji prawomocności stwierdzeń odniesione jest do własności monotoniczności systemu wnioskowań lub braku tej własności.

Implementację aspektów 1, 2, $3 \mathrm{w}$ analizie porównawczej logiki buddyjskiej prezentowałam w artykule Teoria znaczenia i logika Dignagi (Sikora, 2013).

W niniejszym artykule rozważny jest aspekt 4: monotoniczności lub jej braku w koncepcji wnioskowań danego obszaru kulturowego. Ustanawiam tym samym własność monotoniczności wnioskowań jako jedno $\mathrm{Z}$ podstawowych kryteriów badań porównawczych w tym zakresie.

Wcześniej problem monotoniczności jako kryterium porównawcze w logice indyjskiej rozważany był w literaturze przedmiotu w pracach:

3 Zob. artykuł Matilala Epistemology, Logic and Grammar in Indian Philosophical (Matilal 1977) 
Claus Oetke: Ancient Indian logic as a theory of non-monotonic reasoning (1994)

John Taber: Is Indian Logic Nonmonotonic? ( Taber 2004).

Claus Oetke - w pełnej wnikliwości i oryginalności stosowanych metod pracy - przeprowadził analizę porównawczą zbioru systemów wnioskowań, nazwanego przez niego Indian Logic, z powstałą w XX wieku w kulturze zachodniej logika niemonotoniczną. Oto fragment pracy oddający główne założenia prezentowanych przez niego analiz:

The principal aim of this paper is to establish the thesis that a significant relationship exists between Indian theories of proof and inference (anumana), in particular the most ancient varieties of what is commonly called 'Indian Logic,' and a number of quite recent developments in the theory of "commonsense-inference" which are often subsumed under the term 'Non-monotonic Logic(s).'...

...By advocating the existence of far-reaching connections between ancient Indian doctrines of anumana and certain theoretical approaches developed in the framework of "Artificial Intelligence" (AI) it is implied that not only all attempts to equate (these varieties of) Indian theories of inference and proof with Western classical logic(s), and in particular with the Aristotelian doctrine of syllogism, are mistaken, but that also the way of correlating both (kinds of) theories must be revised in a more fundamental degree than it has been advocated even by those scholars who stressed the differences between Indian and Western theories and expressed reservations against equating them too readily. (Oetke 1994: 159-161).

Oetke twierdzi, że istnieje związek obu logik zarówno na „poziomie przedmiotu" jak i na „poziomie teoretycznym". Zakłada, zatem podobieństwo porównywanych logik, zarówno w odniesieniu, co do przedmiotu - teorie wnioskowania - a także w sposobie reprezentacji istotnych cech tych przedmiotów w modelu formalnym. $\mathrm{Na}$ podstawie przeprowadzonej analizy diachronicznej autor artykułu postawił hipotezę, że historyczny rozwój logiki indyjskiej to $\mathrm{w}$ istocie próba przejścia od paradygmatu rozumowania niemonotonicznego do monotonicznego.

W polemice do pracy Oetke, swoje rozważania na temat monotoniczności logiki indyjskiej osadził Taber. Zdaniem Tabera, od samego początku w logice indyjskiej mamy do czynienia z monotonicznym typem wnioskowania. Nazywając je dedukcyjnie poprawnym, uważa, że idea dedukcyjności była w nich stale obecna, lecz koncepcja tego ideału podlegała permanentnej modyfikacji. Kryterium dedukcyjności wnioskowań indyjskich zdaniem autora jest avinabhava (niezmienne wspótwystępowanie), czyli istnienie związku „istotnego" 
Stawomir Sikora: A. Tarskiego kryterium monotoniczności operatora konsekwencji w międzykulturowych badaniach systemów wnioskowań

svabbavapratibandba między częścią wnioskowania zwaną hetu- powód i częścią nazywaną sadhya - skutek. Może on mieć formę związku przyczynowego -tadutpatti lub istotnościowego - tadatmya (Taber, 2004).

Zauważmy, że w obu pracach, autorzy deklarowali badanie własność monotoniczność wnioskowania w logice indyjskiej, dochodząc jednak do odmiennych rezultatów. Oetke uważa, że logiczna analiza natury wnioskowań przedstawianych w pracach indyjskich filozofów pokazuje, że jest ona niemonotoniczna. Taber zaś w opozycji do Oetke argumentuje za ich monotonicznościa.

Stawiam pytanie:jakie cechy winno mieć wnioskowanie, aby można mówić, że są one konstytutywne dla własności monotoniczności wnioskowań w systemach logiki indyjskiej?

Moim zdaniem, dysonans między obu autorami na poziomie formułowania wyników prezentowanej analizy, jest efektem metodologicznego zaniechania. Zarówno Oetke, jak i Tober na podstawowym poziomie analizy nie zadbali o ścisłą definicję przedmiotu badań - jakie wnioskowanie jest wnioskowaniem monotonicznym/niemonotonicznym.

Badali wnioskowania na obecność własności monotoniczności lub jej braku, nie zadbawszy o to, by własność ową na wstępie w ścisły sposób scharakteryzować. W konsekwencji doprowadziło to do efektu, w którym czytelnikowi trudno rozpoznać, czy monotoniczność jest własnością opisywaną na poziomie przedmiotowym, czy też jest narzędziem opisującym na poziomie metateoretycznym.

W rozwiązaniu proponowanym przez mnie ideą podstawową jest, by własność wnioskowań monotoniczność/niemonotoniczność nie była li tylko przedmiotem analogii teoretycznej na zasadzie transferu struktury rozumowania z kultury A do kultury $\mathrm{B}$, lecz metateoretycznym narzędziem opisu, a dalej kryterium porównawczym w analizowanych systemach.

Ujawnia się tym problem badawczy:

monotoniczność jako metodologiczne kryterium wyróżniania $w$ badaniach porównawczych.

\section{Pojecie konsekwencji klasycznej}

W celu przybliżania problemu monotoniczność wnioskowań oraz jego ważkości w rozwiązywaniu problemów nie tylko z nadania teorii, ale i dnia codziennego, proponuję odsłuchanie następującego dialogu:

http://www.polskieradio.pl/7/3086/Artykul/1012065,Kon-jaki-jestkazdy-widzi-Ale-pojazd-to-czy-nie-pojazd-

Z perspektywy historycznej pierwsze systematyczne badania nad relacją konsekwencji logicznej przypadają na pierwszą połowę XX wieku. $\mathrm{W}$ pracy Fundamental concepts of the methodology of the deductive sciences znakomity polski logik Alfred Tarski zaproponował, aby w oparciu 
o pewne operacje, nazywane regutami inferencji, z dowolnego zbioru $A$ można było derywować pewne zdania $x$ nazywane konsekwencjami zbioru $A$. Zbiór wszystkich konsekwencji zbioru $A$ jest zamknięty na dane reguły inferencji (Tarski 1956: 63).

W tej samej pracy, Tarski po raz pierwszy scharakteryzował metateoretyczne własności relacji konsekwencji logicznej. Wydarzenie to w wymiarze historycznym jest nie tylko pierwsze w kulturze zachodniej, lecz również w kulturach innych, w których rozwijane były systemowe badania dotyczące sposobów wnioskowań. Wskazuję w tym względzie na kulturę Indii i Chin. We wszystkich wymienionych kulturach formułowano systemowe własności reguły inferencji, a systemy podawano krytycznej analizie. Każdy $\mathrm{z}$ takich systemów, czy jest to zachodnia sylogistyka Arystotelesa, czy indyjska Hetucakra Dignagi, posiada synkretyczny kulturowo kod inferencyjny. Moim zdaniem, Tarski (sam o tym nie wiedząc) dał badaczom porównawczym narzędzie, dzięki któremu systemy inferencji możemy podać analizie, abstrahując od ich kulturowych determinant - przynajmniej w istotnej ich części.

Innym problemem jest, że badacze zajmujący się badaniami porównawczymi z narzędzie tego korzystali sporadycznie.

Jedną z podstawowych metateoretycznych własności konsekwencji logicznej jest monotoniczność, którą Tarski wyraża następująco:

Niech S będzie zbiorem wszystkich zdań w danej dziedzinie, A oraz B dowolnym zbiorami zdań:

jeżeli $\mathrm{A} \subseteq \mathrm{B} \subseteq \mathrm{S}$ to $\mathrm{Cn}(\mathrm{A}) \subseteq \mathrm{Cn}(\mathrm{B})$

lub ekwiwalentnie:

jeżeli $\mathrm{A}+\mathrm{B} \subseteq \mathrm{S}$ to $\mathrm{A} \subseteq \mathrm{Cn}(\mathrm{B})$ i $\mathrm{Cn}(\mathrm{A}) \subseteq \mathrm{Cn}(\mathrm{B})$.

Współcześnie rzadziej mówi się o relacji domknięcia operatora konsekwencji logicznej ze względu na przedmiotowe reguły inferencji. Domknięcie rozumie się na metapoziomie i wymienia się następujące warunki: zwrotność, kumulatywna przechodniość oraz monotoniczność (Makinson, 2008: 5.)

Za Makinsonem przyjmujemy, że:

$x$ jest klasyczna konsekwencją $A$ wtedy i tylko wtedy, gdy nie istnieje takie wartościowanie, że $v(A)=1$, podczas gdy $v(x)=0$.

Standardowo piszemy: $A \vdash x$, gdzie $\vdash$ znak jest symbolem oznaczającym relację wynikania logicznego. (Kiedy po jego lewej stronie mamy do czynienia ze zbiorem jednoelementowym, notację upraszczamy, opuszczając nawiasy i pisząc: a $\vdash x$, zamiast, $\{\mathrm{a}\} \vdash x)$.

Klasyczna konsekwencja jest relacja między zbiorami formuł lewej strony i pojedynczymi formułami z prawej. Może ona być także opisana 
Stawomir Sikora: A. Tarskiego kryterium monotoniczności operatora konsekwencji $w$ międzykulturowych badaniach systemów wnioskowań

jako pewna operacja działająca na zbiór formul $A$ i dająca w rezultacie większy zbiór $\operatorname{Cn}(A) \mathrm{x}$.

W efekcie operacja konsekwencji gromadzi razem wszystkie formuły, które są konsekwencjami danych przesłanek. Operację konsekwencji klasycznej Cn daje się zdefiniować w oparciu o relację $\vdash$ :

$\mathrm{x} \in \mathrm{Cn}(\mathrm{A})=\{\mathrm{x}: \mathrm{A} \vdash \mathrm{x}\}$

i odwrotnie, wychodząc od operacji Cn, można zdefiniować relację wynikania logicznego $\vdash$ za pomocą następującej definicji:

$A \vdash x$ wtedy i tylko wtedy, gdy $x \in \operatorname{Cn}(A)$.

Zbiór formuł $A$ jest klasycznie niesprzeczny (lub spetniany) wtedy i tylko wtedy, gdy istnieje takie wartościowanie $v$, że $v(\mathrm{~A})=\mathrm{l}, \mathrm{tj} . v(a)-\mathrm{l}$, dla każdego $a \in A$.

W przeciwnym razie powiemy, że zbiór $A$ jest sprzeczny lub (niespetnialny).

Klasyczna konsekwencja oraz niesprzeczność są również pojęciami współ -definiowalnymi:

$A \vdash x$ wtedy i tylko wtedy, gdy zbiór $\{A \cup\{\neg \mathrm{x}\}\}$ jest sprzeczny. Możemy powiedzieć również, że zbiór $A$ jest niesprzeczny wtedy i tylko wtedy, gdy A nie jest konsekwencją logiczna dowolnej kontrtautologii.

Pora obecnie na scharakteryzowanie warunków domknięcia relacji inferencji.

Jeżeli dla dowolnych zbiorów formuł $A, B$ spełnione są następujące warunki, to relacja jest relacją domknięcia konsekwencji logicznej.

Trzy własności charakteryzujące pojęcie relacji domknięcia.

\begin{tabular}{|c|c|}
\hline Zwrotność & $\mathrm{A} \subseteq \mathrm{Cn}(\mathrm{A})$ \\
\hline $\begin{array}{c}\text { Kumulatywść } \\
\text { przechodniość }(C T) \\
\text { lub cięcie }\end{array}$ & $\begin{array}{c}\text { jeśli } \mathrm{A} \subseteq \mathrm{B} \mathrm{i} \mathrm{B} \subseteq \mathrm{Cn}(\mathrm{A}), \operatorname{to} \operatorname{Cn}(\mathrm{B}) \subseteq \mathrm{Cn}(\mathrm{A}) \\
\text { jeśli } \mathrm{A} \subseteq \mathrm{Cn}(\mathrm{B}) \mathrm{i} \mathrm{B} \subseteq \mathrm{Cn}(\mathrm{C}) \text { to } \mathrm{Cn}(\mathrm{A}) \subseteq \mathrm{Cn}(\mathrm{C})\end{array}$ \\
\hline Monotoniczność & $\mathrm{A} \subseteq \mathrm{B}$ to $\mathrm{Cn}(\mathrm{A}) \subseteq \mathrm{Cn}(\mathrm{B})$ \\
\end{tabular}

Klasyczna konsekwencja posiada również własność zwartości, co znaczy, że:

jeśli $\mathrm{x} \in \mathrm{Cn}(\mathrm{A})$, to istnieje taki skończony podzbiór $\mathrm{A}^{\prime} \subseteq \mathrm{A}$, że $\mathrm{x} \in \mathrm{Cn}\left(\mathrm{A}^{\prime}\right)$.

Jeżeli suma zbiorów A i B jest niesprzeczna, to istnieje taki zbiór formuł $\mathrm{A}^{+} \subseteq \mathrm{A}$, który jest maksymalnie niesprzeczny z $\mathrm{B}$. 
Znaczy to jeżeli $\mathrm{A}^{+}$jest niesprzeczny $\mathrm{z} \mathrm{B}$, to nie ma żadnego jego nadzbioru $\mathrm{A}^{++}$, który byłby niesprzeczny z $\mathrm{B}$.

Wszystkie te własności relacji konsekwencji są w tym sensie abstrakcyjne, że nie odnoszą się do żadnych spójników logicznych i z tego powodu moga służyć jako jezzy teorii opisu dla sposobów argumentacji w odmiennych kulturowo systemach filozoficznych.

Przykład. 1.

A: Jeżeli Karino jest koniem, to nie jest pojazdem.

B: Jeżeli Karino nie jest pojazdem, to nie dotycza go przepisy ruchu drogowego.

$x$ : Jeżeli Karino jest koniem, to nie dotycza go przepisy ruchu drogowego.

Wnioskowanie to możemy zapiać $\mathrm{w}$ języku rachunku zdań i otrzymujemy jako formułę:

$$
((p \rightarrow q) \wedge(q \rightarrow r)) \rightarrow(p \rightarrow r)
$$

lub jako schemat wnioskowania:

$B: p \rightarrow q$

A: $\mathrm{q} \rightarrow \mathrm{r}$

Zatem

$\mathrm{x}: \mathrm{p} \rightarrow \mathrm{r}$

Powiemy, że x jest konsekwencją zbioru przesłanek zbioru\{A,B\}, ponieważ nie jest tak, że $\operatorname{gdy} \mathrm{v}(\mathrm{A}, \mathrm{B})=1$ to $\mathrm{v}(\mathrm{x})=\mathrm{O}$.

Relacja konsekwencji, wedle, której prowadzono powyższe wnioskowanie jest monotoniczna, ponieważ jeżeli dołączymy do zbioru $\{\mathrm{A}, \mathrm{B}\}$ dowolną przesłankę np. $\{\mathrm{s}\}$, to warunek, że nie jest tak, że, gdy $\mathrm{v}(\{\mathrm{q} \cup\{\mathrm{A}, \mathrm{B}\}\})=1$ to $\mathrm{v}(\mathrm{x})=\mathrm{O}$ zostanie utrzymany.

\section{Założenia osiowe relacji konsekwencji domyślnej}

$\mathrm{Na}$ co dzień jak i w nauce, podczas dokonywania wnioskowań, nie wszystkie założenia naszych rozumowań są jawne jak w przykładzie 1. 
Stawomir Sikora: A. Tarskiego kryterium monotoniczności operatora konsekwencji w międzykulturowych badaniach systemów wnioskowań

Zwykle tylko kilka z nich wyrażamy explicite, ponieważ mają bezpośredni związek z rozważaną sytuacją lub w jakiś inny sposób zasługują na uwagę. Najbardziej znanym przykładem z literatury dotyczącej problematyki rozumowań niemonotonicznych jest wnioskowanie przedstawione przez R. Reitera w pracy A Logic for Default Reasoning. Autor przedstawia nam wnioskowanie w którym z przesłanki:

A: Kondor jest ptakiem.

wyprowadza się konkluzję

$\mathrm{x}$ : Kondor lata.

Oczywiście wyprowadzenie konkluzji x jest uprawnione tylko wtedy, gdy znamy przesłankę ukrytą w tle:

K: Jeżeli coś jest ptakiem, zatem to coś lata.

Przedstawione rozumowanie umysł wyszkolony logicznie będzie chciał wymodelować $\mathrm{w}$ języku rachunku zdań wedle reguły modus ponens:

$\mathrm{K}: \mathrm{p} \rightarrow \mathrm{g}$

A: $p$

$\mathrm{x}: \mathrm{q}$

Co więcej, umysł taki ustami swojego nosiciela powie, że prawomocność (dedukcyjność) tego wnioskowania zasadza się na tej właśnie regule.

Jeżeli tak jest, to rozumowanie musi być domknięte zarówno na regułę podstawiania RP, jak i regułę odrywania RO.

Ale okazuje się, że we wnioskowaniach z entymematem, z jakim mamy do czynienia wyżej, reguła podstawiania RP nie obowiązuje.

Oto, jeżeli zamiast przesłanki p: Kondor jest ptakiem, podstawimy przesłankę Pingwin jest ptakiem, to rozumowanie straci swoją ważność. Ważność, zatem takiego rozumowania jest ściśle powiązana z przesłanką entymematyczną K.

Przykład miał pokazać pewien mechanizm: podstawianie $\mathrm{w}$ tego rodzaju wnioskowaniach stosuje się tylko do przesłanki wyrażonej jawnie oraz do konkluzji zbudowanej na niej i entymemacie K. Podstawienie nie dotyczy założeń K.

Współczesne badanie tego rodzaju niepewnych wnioskowań sięgają lat siedemdziesiątych poprzedniego stulecia i kojarzone są najczęściej z pracami Mc Carthego. Od pionierskich prac Mc Carthego rozwijana, jest ramach $\mathrm{AI}$, cała grupa różnego rodzaju tego typu badań wnioskowań niepewnych.

W badaniach porównawczych logik $\mathrm{z}$ odmiennych obszarów kulturowych narzędzia metateoretycznego opisu z zasobów AI stosowano 
niezwykle rzadko 4, chociaż ich siła eksplanacyjna w tej materii wydaje się być znacząca.

$\mathrm{Na}$ początku pracy sformułowano cel, którym jest zbadanie metateoretycznych własności relacji konsekwencji $\mathrm{w}$ systemach wnioskowań z obszarów odmiennych kulturowo.

$\mathrm{Z}$ uwagi na postawiony cel, dokonałem wyboru narzędzi metodologicznych, którymi są: teoria niemonotonicznych wnioskowań założeń ukrytych $w$ tle i jej formalne (logiczne) ujęcie przedstawione przez D. Makinsona.

Obecnie zaprezentuję krótką ich charakterystykę formalną, aby w artykule: Niemonotoniczność wnioskowań Hetucakra Digniagi przedstawić próbę implementacji kryterium monotoniczność w analizie porównawczej oparciu o siatkę pojęć i reguł teorii niemonotonicznych wnioskowań założeń ukrytych w tle.

$\mathrm{Na}$ początek wprowadzam definicję paraklasycznej relacji konsekwencji założeń osiowych.

Niech $L$ będzie zbiorem wszystkich formuł FOL. Niech $K \subseteq L$ będzie ustalonym zbiorem formuł, takim, że $K$ będzie reprezentował zbiór założen ukrytych $w$ tle. Niech $A$ będzie dowolnym zbiorem formuł nazywanych przesłankami jawnymi, a c dowolną formułą zwaną konkluzją.

Definicja.1.

Powiemy, że c jest konsekwencją zbioru $A$ ze względu na zbiór założeń ukrytych $K$ (co zapisujemy: $c \in \mathrm{Cn}_{\mathrm{K}}(A)$ lub $A \vdash K c$ wtedy i tylko, gdy nie istnieje wartościowanie takie, że $\mathrm{v}(K \cup A)=1 \mathrm{i}$ jednocześnie $\mathrm{v}(c)=0$.

Zwracamy uwage w tym miejscu na fakt, że tym samym nie można mówić o jednej relacji konsekwencji założeń osiowych lecz wielu. Dokładnie po jednej dla każdego entymematu $K$.

Relacje konsekwencji założeń osiowych są monotoniczne w sensie Tarskiego.

Gdyby zbiór $K$ był domknięty na podstawianie, to relacja konsekwencji byłaby po prostu relacją klasycznej konsekwencji logicznej.

W kroku następnym naszych rozważań umożliwimy, aby przesłanki założenia ze zbioru $K$ zmieniały się w zależności od użytych jawnie przesłanek ze zbioru $A$. Jest to możliwe tylko wtedy, gdy założymy warunek niesprzeczności między zbiorami $K$ i $A$, czyli dopuścimy do zmniejszania ilości używanych przesłanek z $K \mathrm{w}$ przypadku, gdy są one w konflikcie z przesłankami ze zbioru $A$.

Wtasność niemonotoniczność wnioskowania otrzymujemy wtedy, gdy użyjemy maksymalnych podzbiorów $K^{\prime}$ zbioru $K$, które sa niesprzeczne z $A$ i zaakceptujemy jako konsekwencje te

\footnotetext{
4 Przykładem aplikacji epistemicznej teorii zmiany przekonań AGM do badań porównawczych jest praca Nyāya Sũtra jako zmiana epistemiczna ( The Nyāya Sũtra as epistemic change) (Sikora 2012)
} 
Stawomir Sikora: A. Tarskiego kryterium monotoniczności operatora konsekwencji w międzykulturowych badaniach systemów wnioskowań

\section{formuły, które sa konsekwencjami wszystkich takich podzbiorów $K$ '.}

Tak określoną relację będziemy nazywać konsekwencją założeń domyślnych (default-assumption consequence).

Definicja. 2.

Relacja konsekwencji jest konsekwencja założeń domyślnych pewnego zbioru $K$ (co piszemy $\sim_{\mathrm{k}}$ ) wtedy i tylko wtedy i tylko wtedy, gdy \{ $\left.K^{\prime} \cup A\right\} \vdash$ c, dla dowolnego podzbioru $K^{\prime} \subseteq K$, który jest maksymalnie niesprzeczny z $A$.

W odróżnieniu osiowego odpowiednika relacje konsekwencji założeń domyślnych są niemonotoniczne. Zatem może być tak, że A $\sim \mathrm{k} x$, ale jednocześnie, kiedy dołączymy do A pewną przesłankę $\mathrm{B}$, to $\{\mathrm{A} \cup \mathrm{B}\} \not x$, gdzie A, B są zbiorami zdań.

Ponieważ monotoniczność niekiedy nie zachodzi, więc operacje konsekwencji domyślnych założeń nie są na ogół operacjami domknięcia.

W celu pokazania, że monotoniczność nie musi zachodzić, zanalizujemy następujący przykład:

Przykład. 3.

Przesłanka jawna -

A: Karino jest koniem.

Konkluzja -

c: Karino nie dotycza przepisy ruchu drogowego.

Założenia domyślne -

K: Jeżeli Karino jest koniem to nie jest pojazdem. Jeżeli Karino nie jest pojazdem, to nie dotycza jego przepisy ruchu drogowego.

Wnioskowanie zapisujemy $\mathrm{w}$ formie schematu:

$A: \mathrm{p}$

$c: \mathrm{r}$

$K:\{\mathrm{p} \rightarrow \mathrm{q}, \mathrm{q} \rightarrow \mathrm{r}\}$

Zbiorem założeń domyślnych $\mathrm{K}$ będzie założenie:

K:\{Jeżeli Karino jest koniem, to nie jest pojazdem. Jeżeli Karino nie jest pojazdem, to nie dotycza go przepisy ruchu drogowego\} 
Otrzymujemy $\mathrm{p} \sim \mathrm{K} \mathrm{r}$ ponieważ przesłanka $\mathrm{p}$ jest niesprzeczna $\mathrm{z} \mathrm{K}$, oraz $\{\mathrm{K} \cup \mathrm{p}\} \vdash \mathrm{r}$.

Jednak sytuacja ulega zmianie, gdy wobec nowych okoliczności przyjmujemy inną przesłankę jawną np.:

$\{$ Karino jest koniem, Karino jest pojazdem $\}$ czyli $\{\mathrm{p}, \neg \mathrm{q}\}$.

$\mathrm{W}$ takim przypadku $\{\mathrm{p}, \neg \mathrm{q}\} \not \subset \mathrm{K}$ r, ponieważ nowa przesłanka A jest sprzeczna ze zbiorem $\mathrm{K}$.

Istnieje jeden maksymalny podzbiór $\mathrm{K}^{\prime} \subseteq \mathrm{K}$, który jest niesprzeczny $\mathrm{z}$ $\mathrm{K}$. Jest to pojedyncza formuła $\mathrm{K}^{\prime}-\{\mathrm{q} \rightarrow \mathrm{r}\}$.

Konkluzja wnioskowania $\{r\}$ nie jest już jednak konsekwencją logiczną sumy zbioru $\left\{\{\mathrm{p}, \neg \mathrm{q}\} \cup \mathrm{K}^{\prime}\right\}$

Stąd możesz wnioskować, że Karino jest koniem, jak również, że Karino nie jest koniem.

Relacja konsekwencji założeń domyślnych na poziomie metateorii nie jest monotoniczna, ale ma własność kumulatywnej przechodniość.

W badaniach porównawczy przydatnym może okazać się własność tego rodzaju logik, którą określa się mianem osłabionej racjonalność.

Jeżeli $A \sim_{\mathrm{K}} c$ to $\{A \cup\{B\}\} \sim_{\mathrm{K}} \mathrm{c} \operatorname{lub} A \vdash_{\mathrm{K}} \neg \mathrm{c}$.

\section{Konkluzja}

W dotychczasowej metodologii badań porównawczych systemów logiki z obszarów odmiennych kulturowo, kryterium monotoniczność stosowane było śladowo. Co prawa w pracy John Tabera i Clausa Oetke własność monotoniczność wnioskowań w logice indyjskiej została poddania analizie, jednak, jak uważam, brak odwołania się w warstwie metodologicznej obu prac do źródłowego i jednoznacznego rozumienia tej własności zaowocował odmiennymi rezultatami u obu autorów. Drugim z powodów rozbieżności był fakt, że logika indyjska w odróżnieniu o jej zachodniej siostry, nie jest jednorodna w swoim rozwoju i może być tak, że w ramach tego samego systemu dopuszcza się wnioskowania monotoniczne, nazywając je pewnymi i jednocześnie niemonotoniczne nazywając niepewnymi.

Wykorzystanie tego kryterium w metodologii badań porównawczych przyniesie efektywne rezultaty wtedy, gdy oparte będzie na definicji operatora konsekwencji sformułowanej przez A. Tarskiego, tak jak czyni się to na gruncie sformalizowanych logik niemonotonicznych. Implementację tego zabiegu metodologicznego prezentuję w artykule Niemonotoniczność wnioskowań Hetucakra Dignagi, który stanowi II część sprawozdania z prowadzonych badań. 
Stawomir Sikora: A. Tarskiego kryterium monotoniczności operatora konsekwencji w międzykulturowych badaniach systemów wnioskowań

\section{Bibliografia}

Antonelli, G.A. 1997. Defeasible inheritance over cyclic networks. Artificial Intelligence. Vol. 92 (1), s. 1-23.

,--- 1999 . A directly cautious theory of defeasible consequence for default logic via the notion of general extension. Artificial Intelligence, 109 (1-2), s. 71109.

---, 2005. Grounded Consequence for Defeasible Logic. Cambridge. Cambridge University Press.

Chellas, B. 1980. Modal Logic: an introduction. Cambridge. Cambridge University Press.

Daye, D.D. 1975. Remarks on Early Buddhist Proto - Formalism (Logic) and Mr. Tachikawa's Translation of the Nyayapravesa. Journal of Indian Philosophy 3, s. $383-398$.

Daye, D. D. 1977. Metalogical incompatibilittes in the formal description of buddhist logic (nyaya). Notre Dame Journal of Formal Logic. Vol. XVIII, Number 2.

Gabbay, D. M. 1985. Theoretical foundations for nonmonotonic reasoning in expert systems. W: K. Apt (ed.), Logics and Models of Concurrent Systems, Berlin and New York. Springer Verlag, s. 439-459.

Gabbay, D., Hogger, C. and Robinson, J., (eds.). 1994. Handbook of Logic in Artificial Intelligence and Logic Programming. Vol. 3, Oxford and New York. Oxford University Press.

Ginsberg, M. (ed.).1987. Readings in Nonmonotonic Reasoning. Los Altos, CA: Morgan Kauffman.

Harbsmeier, Ch.1998. Language and Logic. Science and civilisation in China. Vol. 7. CUP.

Hughes, G. and Cresswell, M. 1996. A New Introduction to Modal Logic. London. Routledge.

Horty, J.F. 1994. Some direct theories of nonmonotonic inheritance. In Gabbay et al. (1994), s. 111-187.

---, 2002. Skepticism and floating conclusions. Artificial Intelligence Journal, 135, s. 55-72.

Kautz, H. and Selman, B. 1991. Hard problems for simple default logic, Artificial Intelligence Journal, 49, s. 243-279

Kripke, S. 1975. Outline of a theory of truth, The Journal of Philosophy, 72, s. $690-716$.

Lifschitz, V. 1993. Circumscription, in Gabbay, Hogger, and Robinson (eds.) 1994.

Makinson, D. 2008. Od logiki klasycznej do niemonotonicznej. Wydawnictwo Naukowe Uniwersytetu im. M. Kopernika w Toruniu.

Matilal, B.K. 1971. Epistemology, Logic and Grammar in Indian Philosophical Analysi,. Mouton, the Hage. Paris.

McCarthy, J. 1980. Circumscription - A Form of Non-Monotonic Reasoning. Artificial Inteligence, 13, s. 27-39. 
---, 1986. "Applications of Circumscription to Formalizing Common Sense Knowledge”. Artificial Inteligence, 28, s. 89-116.

,--- 1990 . Formalization of common sense. Papers by John McCarthy edited by $V$. Lifschitz, Ablex.

Oetke, C. 1996. Ancient indian logic as a theory of non-monotonic reasoning. „Jurnal of Indian Philosphy” nr. 24 (5), s. 447-539 (1996).

Radhakirishna, Ch. 1948. Indian Philosophy, London. George Allen and Unwin Ldt.

Schayer, S. 1932. Studien zur indischen Logik. I. Der indische und der aristotelische Syllogismus. Bulletin International de l'Academie Polonaise des Sciences et de Lettres.

Sikora, S 2012. Logika Dignāgi - problemy interpretacji (Dignāga's Logic problems of interpretation). Investigationes Linguisticae. Vol. XXV, 2012, s. 127-156.

Sikora, S. 2012, Nyāya Sũtra jako zmiana epistemiczna ( The Nyāya Sũtra as epistemic change) Investigationes Linguisticae. Vol. XXVI, 2012, s. 82-107.

Stalnaker, R. 1994. Nonmonotonic consequence relation, Fundamenta Informaticae, 21, s. 7-21.

Taber, J. 2004. Is Indian Logic Nonmonotonic? Philosophy East and West, Vol. 54, Number 2, April 2004, s. 143-170.

Tarski, A. 1956. Logic, semantic, metamathematic, Papers from 1929 - 1938. OUP. DOI: 10.1353/pew.20. 